\title{
Erratum to: Race, ethnicity, and the duration of untreated psychosis: a systematic review
}

\author{
Kelly K. Anderson $\cdot$ Nina Flora $\cdot$ Suzanne Archie $\cdot$ \\ Craig Morgan $\cdot$ Kwame McKenzie
}

Published online: 7 December 2013

(C) Springer-Verlag Berlin Heidelberg 2013

Erratum to: Soc Psychiatry Psychiatr Epidemiol

DOI 10.1007/s00127-013-0786-8

Table 3 was incorrectly formatted during the production process. The corrected version of Table 3 is shown below:

The online version of the original article can be found under doi:10.1007/s00127-013-0786-8.

K. K. Anderson $(\bowtie) \cdot N$. Flora $\cdot$ K. McKenzie

Social and Epidemiological Research, Centre for Addiction and

Mental Health (CAMH), 455 Spadina Avenue, Suite 300,

Toronto, ON M5S 2G8, Canada

e-mail: kelly.anderson@camh.ca

\section{S. Archie}

Department of Psychiatry and Behavioural Neurosciences, McMaster University, 25 Charlton Avenue East, Suite 703,

Hamilton, ON L8N 1Y2, Canada

\section{Morgan}

Section of Social Psychiatry, Institute of Psychiatry, King's College London, De Crespigny Park, London SE5 8AF, UK

\section{K. McKenzie}

Department of Psychiatry, University of Toronto, 455 Spadina

Avenue, Suite 300, Toronto, ON M5S 2G8, Canada 


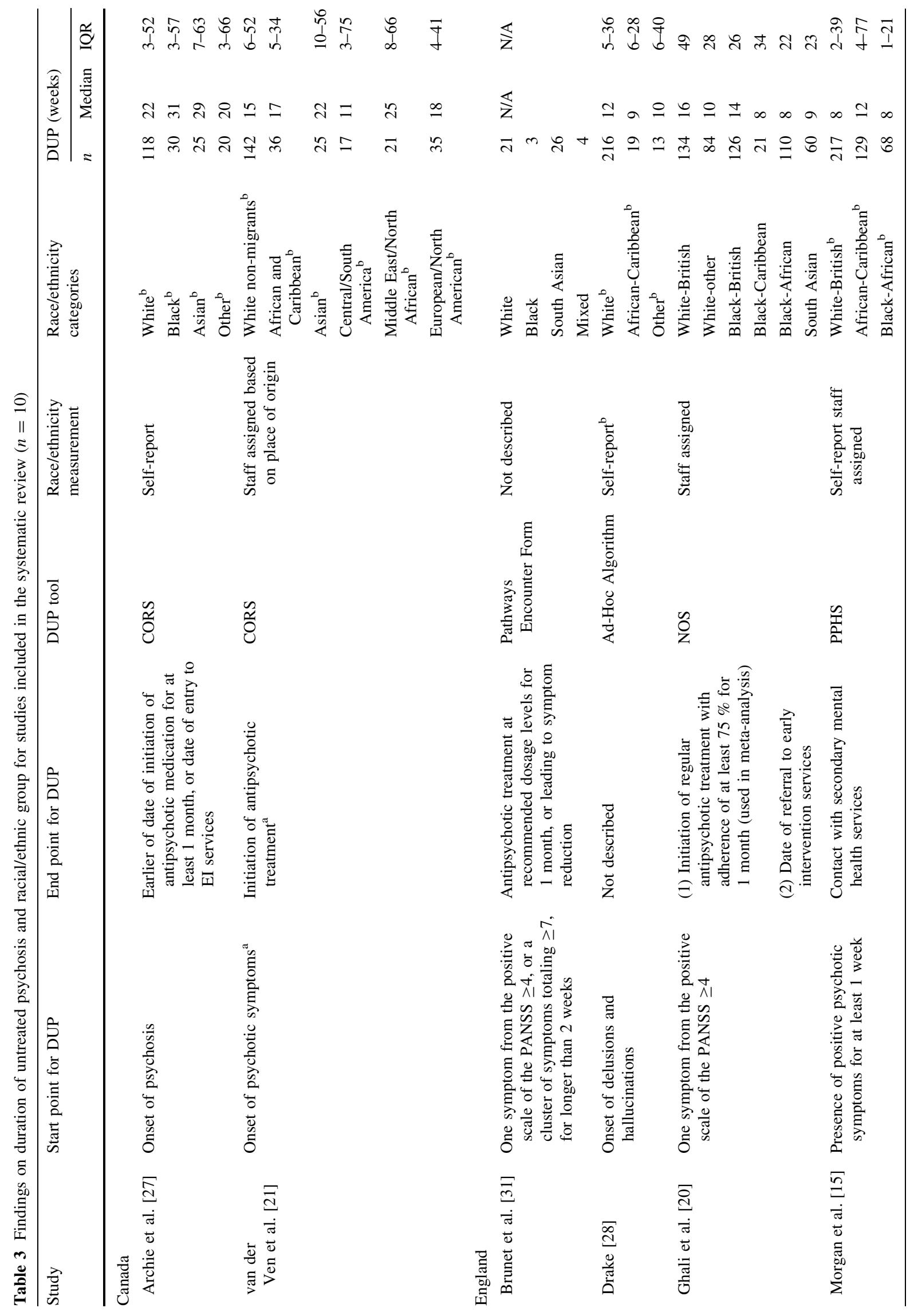




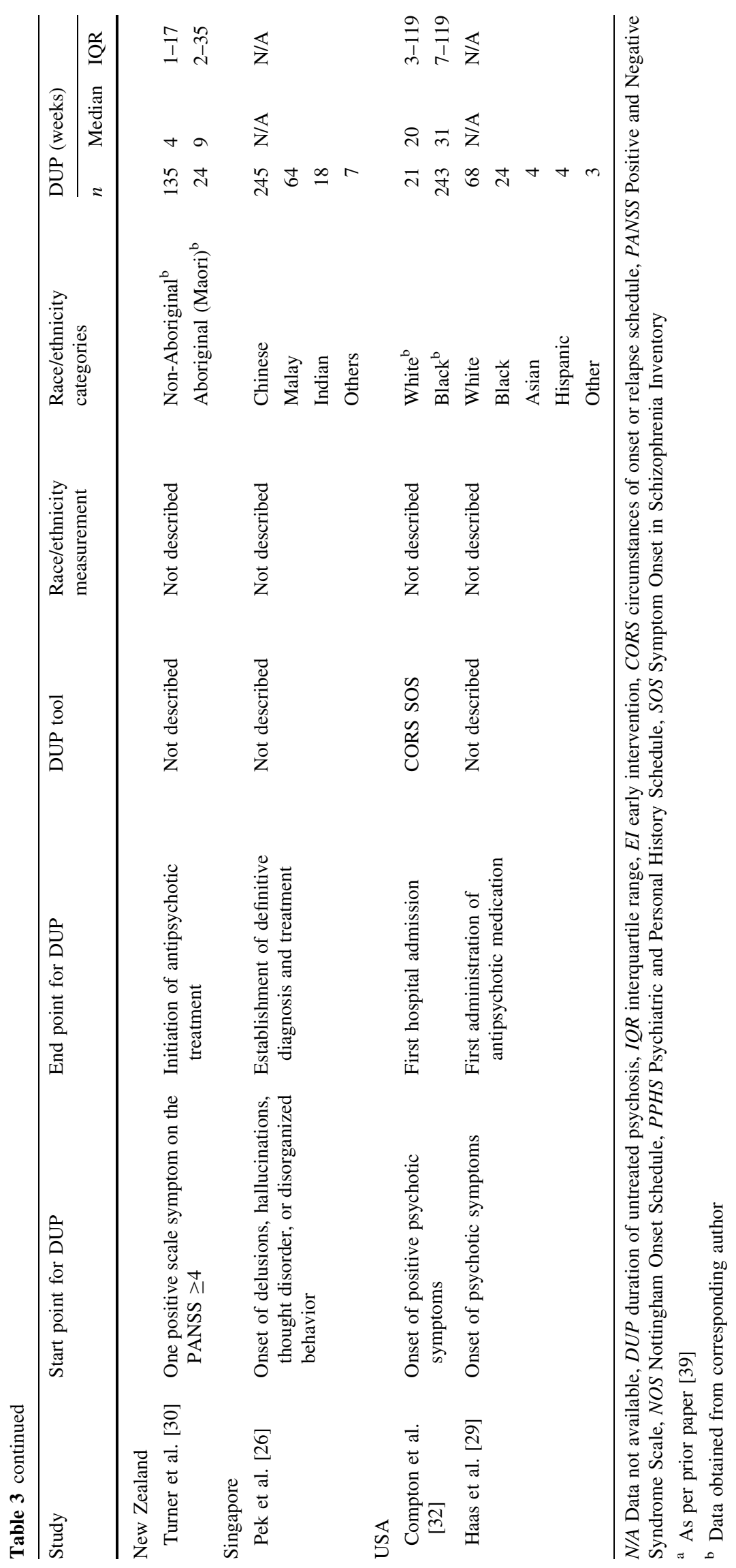

